\title{
Implementing a Freshman Engineering Design Experience at the University of Washington
}

\section{Fabien, Brian ${ }^{\mathrm{b}}$ and Vereen, Keon ${ }^{\mathrm{a}}$}

${ }^{\mathrm{a}}$ Department of Aeronautics and Astronautics, ${ }^{\mathrm{b}}$ Department of Mechanical Engineering, University of Washington, USA.

\begin{abstract}
A project-oriented introductory engineering design course has been developed within the University of Washington's College of Engineering to enhance the first-year student experience. The role of engineering was demystified, explaining the difference between trade specialists and engineers. The students learned that the "art of engineering" is in solving complex problems. Throughout the course, students learned about programming, computer-aided design, and $3 D$ printer technology to assist in the development of team projects. As each new prototype was unveiled, teams learned important lessons about the transition from conception to implementation. One of the biggest outcomes of the course was learning to work effectively in teams. At the end of the course, each team was assessed not only on quality of design project but also team efficacy. The students developed their professional socialization skills while preparing technical reports and oral (PowerPoint and poster) presentations. On the closing day of the program, students presented their group projects in front of campus and industry partners.
\end{abstract}

Keywords: Introduction to engineering; project-based courses; first-year courses. 


\section{Introduction}

Engineering design courses have been identified as important pedagogical practices over the years to improve retention, student motivation and satisfaction, diversity, and student learning. Dalley and Zhang (1993) noted the design, build, test approach to be an effective pedagogical strategy to motivate students and develop their critical thinking skills. Dutson, et al. (1997) forecasted the increase in design courses in engineering curricula as a pathway toward better prepared graduates. Dym, et al. (2005) mentioned an improvement in professional socialization skills, noting the engineering design process as a social process, in which teams define and negotiate project design solutions. Borgford-Parnell, et al. (2010) discussed the effectiveness of project-based learning, highlighting how design project autonomy allows for authentic design experience and opportunites to reflect and learn from design processes. In an age of globalization, the National Academy of Engineering (Vest, 2005) has stated that future engineers must be trained to become experts in a variety of subjects and fields to solve complex global problems.

The University of Washington College of Engineering has developed a new engineering design course to provide an experiential learning experience to incoming freshman students. The course was intended to be rigorous, teaching design fundamentals that excite students about opportunities within the field of engineering. The design course was first piloted during an intensive Women in Science and Engineering (WiSE) summer bridge program. The instructor taught twenty incoming freshman about the engineering design process, programming, computer-aided design, and 3D printer technology. In a $4 \frac{1 / 2}{2}$ week course, students were able to design, build, and test design projects i.e. bridges, gears, rockets, and robots. Based on the outcome of the initial course, the program was scaled up to accommodate 100 students during a 10 -week academic quarter.

\section{Methodology}

The newest version of the course had an instruction team consisting of a lecturer, three teaching assistants, and a laboratory shop manager. The goal was to provide students a broad perspective on engineering and help them decide on a career in engineering. There were two sections: a lecture component and a lab component. In the lecture section, the instructor taught students foundational mechanical and electrical principles. In the lab section, teams applied these principles to design, build, and test challenging projects centered on energy, environment, health, infrastructure, and exploration. The teaching assistants and laboratory shop manager provided additional content and development expertise throughout the quarter. The core components of the class were technical content and design, technical communication, and professional skills. 


\subsection{Lecture format}

The lectures covered the engineering profession, professional standards and practices, the engineering design process, and laboratory shop skills. Throughout the quarter, rhetorical questions and "think, pair, share" pedagogical strategies were frequently used to engage the entire classroom. In addition, university and industry partners were invited to speak to the class about engineering design and its relevance in the public and private sectors. The UW Center for Engineering Learning \& Teaching fostered a conversation on "how to work effectively in teams", creating an environment to discuss teamwork and formulate an accountability plan.

A layout of the lectures taught are shown in Table 1. In the first week, an overview of engineering was presented. The second week discussed the importance of multidisciplinary teams, effective team communication, and engineering code of conduct and ethics. In the third week, the engineering design process was discussed. The simplest form is the 3 -step: design, build, and test loop. For this course, an 11-step was chosen to provide students enough specifics while allowing for flexibility. The 11-step process is outlined in Table 2. In the fourth week, the importance of engineering drawings were discussed. Computeraided design was introduced as an important tool engineers use to transform conceptual ideas, i.e. napkin sketches, into actual three-dimensional models. Students used either Autodesk Inventor or Solidworks as modelling software to design their projects. In the fifth week, students learned the difference between conventional manufacturing i.e. drill press, mill, lathe, band saw and additive manufacturing i.e., 3D printing. For design projects, 3D printing would be used to rapid prototype of parts for project assembly. General machine shop safety, rules, and regulations were also discussed. In the sixth week, fundamental engineering principles were covered broadly, relevant to design projects i.e. mass, momentum, energy, pressure, work, power, etc. In the seventh week, an introduction to electrical components, circuit design, and microcontroller operation were covered. The class spent time discussing how to program in Arduino's open source software. In the eighth week, students learning programming in Python principles, relevant to control and analysis of design projects. In the ninth week, students learned engineering statistics and probability and how to collect and analysis data from projects. In the tenth week, class was setup as an open lecture, allowing teams to work on final design iterations and/or ask instruction team for final feedback prior to engineering symposium day. 
Table 1: Lecture Sessions

\begin{tabular}{|l|}
\hline Engineering Instruction \\
\hline Week 1: Syllabus \& Introduction to Engineering \\
\hline Week 2: Engineering Design Challenges \& Professional Skills \\
\hline Week 3: Engineering Design Process \& Communication \\
\hline Week 4: Engineering Drawings, Computer-aided Design \\
\hline Week 5: Safety, Prototype Construction \\
\hline Week 6: Fundamental Principles \\
\hline Week 7: Introduction to Electrical Circuits \\
\hline Week 8: Introduction to Programming \\
\hline Week 9: Engineering Analysis \\
\hline Week 10: Open Lecture - Engineering Design Final Iterations \\
\hline
\end{tabular}

Table 2: 11-step Engineering Design Process

(1) Understand - define the problem

(2) Explore - do background research

(3) Define - determine solution specifications

(4) Ideate - generate conceptual solutions

(5) Prototype - learn how concepts work

(6) Choose - determine a finl concept using a weighted objectives table

(7) Refine - do detailed design

(8) Present - get feedback and final approval

(9) Implement - build the detailed solution

(10) Test - does the solution work?

(11) Iterate - repeat the cycle if desired outcome not obtained 


\subsection{Laboratory Format}

A breakdown of the week-to-week labs are shown in Table 3. The labs occurred in a new laboratory facility located in a student dormatory. The laboratory facility was a minimachine shop with 3D printers, laser cutters, soldering stations, and cutting and drilling equipment. In the first few weeks of the quarter, three impromptu design challenges were introduced to build team camaraderie and enhance active learning. These challenges included a slow descending aerial vehicle, a tallest tower, and a catapult. After teambonding exercises, teams finalized their design projects, selecting from a list of twenty distinct design challenges. The types of selected design projects are shown in Figure 1. Each team was given access to similar resources, i.e. access to modelling software, machining tools, nuts and bolts, electrical components, Arduino kits, and Flash Forge Creator Pro 3D printers. For each design challenge, each team had to satisfy design constraints and meet functional requirements. All design teams were constrained by a preallocated budget and limited time. A list of the specifications for some of the design challenges is presented below.

- Prosthetic Hand/Arm Design Challenge: A team of engineers has been tasked to build an Arduino-controlled prosthetic hand/arm. The prototype must be a functional realistic design, with the ability to move freely or grip an object.

- Unmanned Aerial Vehicle Design Challenge: A team of engineers has been tasked to build the most efficient Arduino-controlled unmanned aerial vehicle. The prototype must be functional, with the ability to move vertically upward. The team had to predict the maximum height and time of flight for their specific designs.

- Robot Design Challenge: A team of engineers has been tasked to build the most efficient, creative Arduino-controlled robot system. The prototype must be able to move freely in at least one direction. The team had to predict how far and fast their vehicle would travel.

- Submersible Vehicle Design Challenge: A team of engineers has been tasked to build the most efficient, aesthetically pleasing Arduino-controlled submersible vehicle. The prototype must be waterproof with the ability to move freely in one direction, above or below water, without sinking below a desired depth. 
Table 3: Laboratory Sessions

\begin{tabular}{|l|}
\hline Engineering Laboratory \\
\hline Week1: Pick Design Teams \\
\hline Week 2: Impromptu Design Challenges \\
\hline Week 3: Engineering Design Process (EDP) Development \\
\hline Week 4: Team CAD Work \\
\hline Week 5: Team CAD Work \& EDP Presentations \\
\hline Week 6: Prototype Development \\
\hline Week 7: Prototype Development \\
\hline Week 8: Programming using Python/Arduino IDE software \\
\hline Week 9: Programming \& Engineering Analysis \\
\hline Week 10: Final Design Iterations \& Mock Presentations \\
\hline Finals Week: Engineering Symposium Day \\
\hline
\end{tabular}

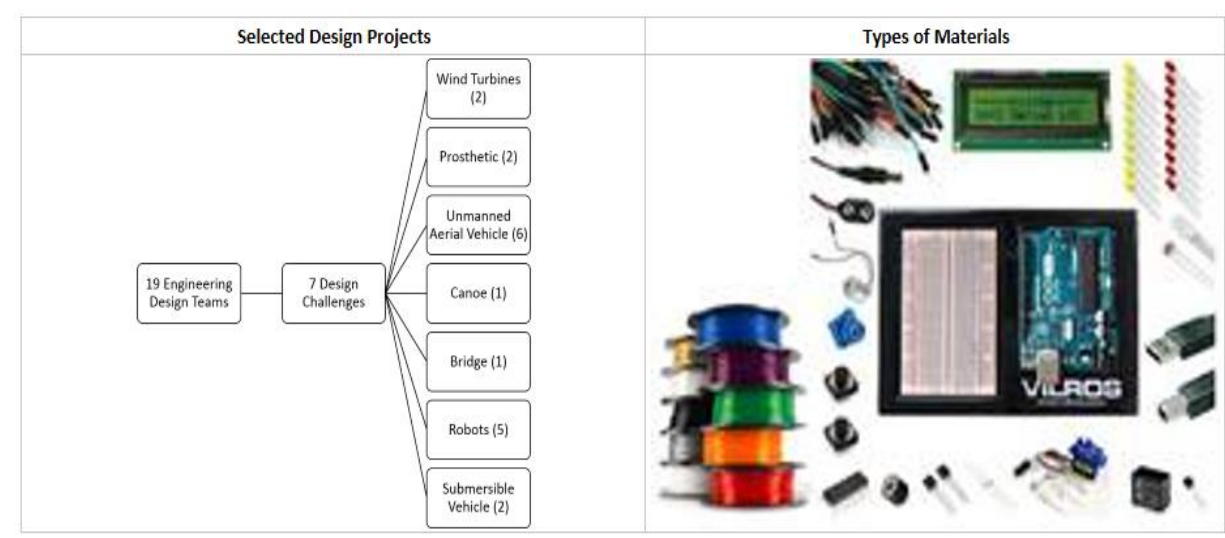

Figure 1: Selected Projects and List of Materials 


\subsection{Course Assesment}

Based on the work by Moore (1994) in an introductory electrical engineering design course, a holistic grading scheme was used to evaluate student and team performance. Students were evaluated based on completion of reflection exercises and team-oriented activities. Reflection exercises represented $20 \%$ of overall student score. Team-oriented activities toward the development of design projects represented $80 \%$ of overall student score. A list of course assignments is shown below.

- Engineering Assessments: Bi-weekly reflection exercises were used to enhance student comprehension and transformation of lecture and laboratory content.

- Team Contracts: Teams developed an agreement amongst team members that outlines roles and priorities toward project design success. Each member pledged to distribute work evenly and build consensus in the event of conflicts.

- Engineering Design Process Presentations: Teams developed Powerpoint presentations, providing a status update to the instruction team. These presentations were used as mid-quarter preliminary design review sessions, providing constructive feedback.

- Team Progress Reports: A two page document that outlines the team's design challenge, background research, and methodology.

- Mock Presentations: Final design review sessions, providing last minute feedback prior to teams presenting prototype in front of the college and industry partners.

- Engineering Binders: Teams were required to document the product development process from conception to implementation. Each team needed to include their team contracts, engineering design process, progress reports, final reports, and assessments.

- Design Posters: Teams presented a poster at the engineering symposium day, displaying the engineering design process and final product development.

\subsection{Individual Scores}

As mentioned earlier, the instruction team decided to assign $20 \%$ of overall student score based on the completion of four reflection exercises. The remaining $80 \%$ of overall student score was allocated based on student participation within team-oriented activities. Student participation acted as a multiplier of overall team score. $100 \%$ student involvement in team activities yielded full team score. Student participation was assessed using both visual diagnostic, i.e. instruction team observing student involvement in labs, and anonymous peer evaluation forms submitted online to instruction team. There were two peer evaluation forms, one mid-quarter and the second at the end of the quarter, to assess individual student contribution to team product design. The two peer evaluation forms were averaged to determine a variance for grade allocation. 


\section{Results and Discussion}

\subsection{Final Product Development}

The design teams presented their projects during finals week at an engineering symposium day to showcase their cornerstone projects to the UW College of Engineering community and affliated partners. Some of the design teams are highlighted in Figure 2. There were three components being judged at the showcase: (1) design products, (2) engineering binders, and (3) team posters. The team with highest marks in all three categories received the top design award, receiving recognition from their peers and the UW College of Engineering community. Moreover, all teams received positive, constructive feedback from instruction team and showcase attendees.

\subsection{Student Responses}

At the end of the course, students provided an evaluation of their overall feelings about the course. A sample of selected responses have been included below.

- 'I'm particularly happy with the fact that my project had a controls aspect and that I had a chance to learn to interact with Arduino. This design project fits well with my major which is electrical engineering."

- "I enjoyed the design project. It was quite fun to go through the trial and error to find the design that best solved our UAV challenge. My major choice is mechanical engineering, so I plan to work on project team interested in building a waterproof submarine made of PLA."

- "I thought our race car project was fun and overly successful. Going forward, I'm interested in creating an app for android that could be used to control the car over wifi. This will be within mechanical engineering."

- "Overall, I am very happy with our design project. Our goals were to build a prosthetic arm with the time and budget we were given and I am happy to say we have satisfied both those goals! I will apply what I learned during this design project toward my next project team, EcoCAR." 


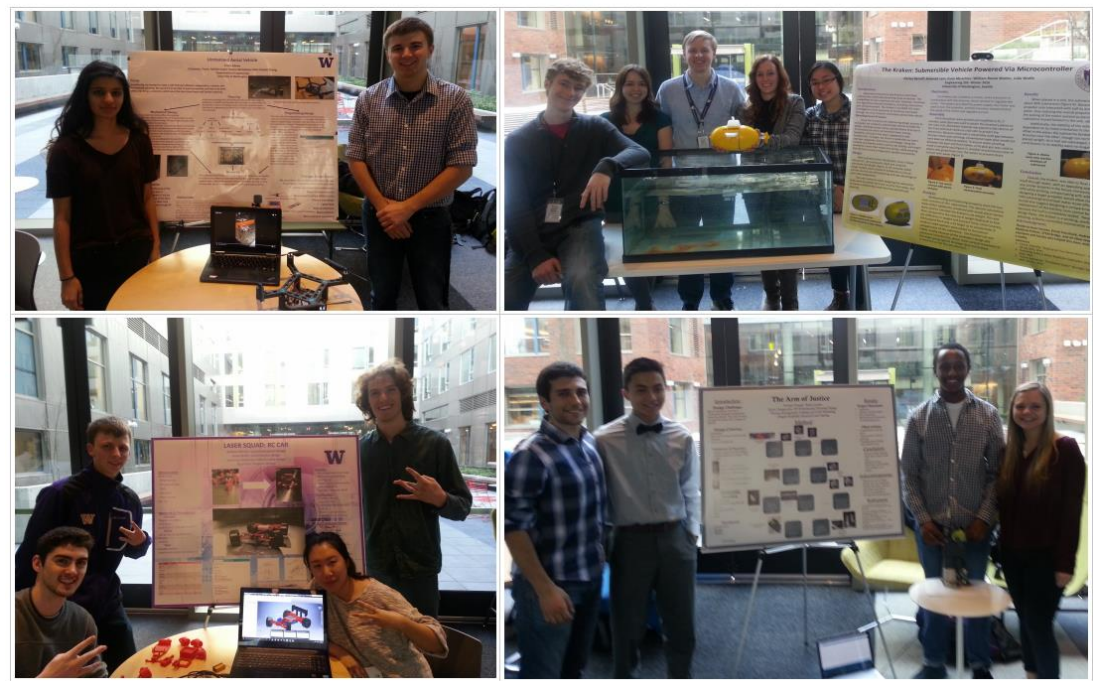

Figure 2: Top Left - Unmanned Aerial Vehicle, Top Right - Submersible Vehicle, Bottom Left-Robotic Vehicle, Bottom Right - Prosthetic Arm.

\subsection{Discussion}

The instruction team saw student growth in the areas of modelling, 3D printing, coding, and product development. A diverse team of students, from various scientific and cultural backgrounds, learned to work effectively to create elegant project design solutions. Overall, the course was successful in providing first year experiential learning, allowing students to transfer newfound knowledge to future classes and project design teams. The course can be improved by accommodating more open-ended design projects that fit within the UW College of Engineering themes.

\section{Conclusion}

A new introductory engineering design course was developed at the University of Washington to provide hands-on experience to freshman students. The 10-week course challenged students to be creative and collaborative with their teams to develop a functional product. Students mentioned an increase in engagement in pre-requisite and engineering fundamental courses while taking the design course concurrently. Going forward, a \$30 student user fee will be included in future offerings of the course to cover the entire cost of laboratory supplies, equipment, and maintenance. The course will include more Arduinoactuated design projects, with project team guidance from upper division undergraduates. The upper division undergraduates will receive academic leadership credits, serving as emerging scholars who mentor and oversee project development of freshman design teams. 


\section{References}

Borgford-Parnell, J., Deibel, K., and Atman, C. J., (2010). From engineering design research to engineering pedagogy: Bringing research results directly to the students. International Journal of Engineering Education, 26(4), 748.

Dally, J. W., and Zhang, G. M. (1993). A freshman engineering design course. Journal of Engineering Education, 82(2), 83-91.

Dutson, A. J., et al. (1997). A Review of Literature on Teaching Engineering Design Through Project-Oriented Capstone Courses. Journal of Engineering Education, 86(1), 17-28.

Dym, C. L., et al. (2005). Engineering design thinking, teaching, and learning. Journal of Engineering Education, 94(1), 103-120.

Moore, D., (1994). A practical approach to introductory level design in electrical Engineering. Frontiers in Education Conference, 1994. Twenty-fourth Annual Conference. Proceedings IEEE.

Vest, C. M., (2005). Educating engineers for 2020 and beyond. National Academy of Engineering. 